\title{
Impact of Radical Terracing on Chemical Properties of the Soil a Case of Nyabihu District, Rwanda
}

\author{
Niragire Ezechiel, Maniragaba Abias \\ Department of Environmental Economics and Natural Resources Management, University of Lay Adventists of Kigali, Kigali, Rwanda
}

Email address:

ezeniragire@gmail.com (N. Ezechiel)

\section{To cite this article:}

Niragire Ezechiel, Maniragaba Abias. Impact of Radical Terracing on Chemical Properties of the Soil a Case of Nyabihu District, Rwanda. International Journal of Natural Resource Ecology and Management. Vol. 4, No. 2, 2019, pp. 50-54. doi: 10.11648/j.ijnrem.20190402.13

Received: March 12, 2019; Accepted: April 30, 2019; Published: June 3, 2019

\begin{abstract}
Cultivation on steep slopes without any kind of soil conservation methods causes' major erosion phenomenon, in Nyabihu District of Rwanda radical terraces has been implemented in order to decrease soil erosion effect. This study aimed at assessing the impact of this radical terracing on the soil chemical properties. Soil samples was collected before and after terracing and analyzed for $\mathrm{pH}$, organic matter, available phosphorous, exchangeable calcium, magnesium and potassium; cation exchange capacity, total nitrogen and total exchangeable acidity. The $\mathrm{pH}$ and organic matter was analyzed respectively using a pH-meter and calcinations method, while the available phosphorous were obtained using the MEHLICH III method, exchangeable $\mathrm{Ca}^{2+}$ and $\mathrm{Mg}^{2+}$ by titrimetric, potassium, cation exchange capacity, total nitrogen and total exchangeable acidity were determined using the K-kit method, Nessler method, mineralization and titrimetric method respectively. The results from the soil samples analyzed showed that terracing have an impact on soil chemical properties of the soil. All the studied properties decreased except the total exchangeable acidity which increased, therefore, the soil after terracing needs improvement of its fertility and productivity; through sufficient agricultural inputs both mineral and organic.
\end{abstract}

Keywords: Soil, Terracing, Chemical Properties, Agricultural Input

\section{Introduction}

Soils are that portion of earth in which land plant can grow, if water and temperature are adequate [1]; Soil has four major components. They are mineral matter $(45 \%)$, organic matter $(5 \%)$, soil air (25\%) and soil water (25\%) [2].

Globally, land is degraded due soil erosion which has turned into a major agricultural and environmental problem worldwide [3] and it remain significant threats for most agricultural lands [4] and constitute a limiting factor for the per capita food production growth in several locations especially in the African countries [5-6].

In Rwanda land degradation constitutes significantly to poor of the agricultural sector, which is a key pillar of the Rwandan economy. The decrease in soil productivity and yield as a consequence of continued land degradation is a serious threat to sustainable livelihoods for the rural population and it is a major factor of the high level of poverty in the country side. Land degradation implies reduction of resource potential by one or a combination of processes acting on land. These processes include water erosion, wind erosion, and sedimentation by those agents, resulting in long term reduction in amount or diversity of natural vegetation, etc. water erosion is a general problem in Rwanda where rainfall in mountains plays an important role in soil degradation [7].

Consequently, sustainable land use management and specifically soil conservation has been clearly emphasized on, as critical for the country's long-term development [8]. The conservation of soil should aim at multi-faceted approach involving biological and mechanical measures. There are many biological measures that are used in Rwanda, and in the areas where biological measures are not sufficient to achieve the objectives of water and soil conservation, mechanical measures, such as: anti erosion trenches, progressive terraces and radical (bench) terraces are adopted [9]. In Nyabihu District of Rwanda bench terrace has been implemented in order to decrease soil erosion effect.

The aim of this research was to assess the impact of terracing on soil chemical properties. This was achieved by making a comparative study on different samples of the soil before and after terracing in order to contribute to a better understanding of the impact of this terrace on the chemical parameters of this soil 
before and after terracing and recommend different amendment needed to increase the productivity of this soil.

\section{Materials and Methods}

Six composite samples have been collected using a hand soil auger, before and after terracing, each composite sample was made of 10 single samples.

The materials used for analyzing were the following: plastic bottles, SSFA, shaker, $\mathrm{pH}$-meter, plastic cylinder, $250 \mathrm{ml}$ erlenmeyers, oven, and $100 \mathrm{ml}$ volumetric flasks, filter papers, automatic burette, distilled water, hot plate, pipette, distiller, beakers, sieve, analytical balance and Didester.

All chemicals used were of analytical grade. They included: potassium chloride (1N), Sodium Hydroxide (0.01N), Mehlich III, Ammonium Acetate, ethanol 96\%, Acidified sodium chloride 10\%, hexacyanoferrate (II) of potassium, Hydroxylamine-hydrochloride, calcon, methanol, ethylene diamine tetra acetic acid (salt disodic), Eriochrome black and concentrated sulphuric acid. The soil samples were dried at room-temperature in UR-CAVM laboratories. Then they were ground and passed through $2 \mathrm{~mm}$ and $0.5 \mathrm{~mm}$ sieve for analysis using different method such as: calcinations, titrimetric, Nessler, mehlich III and mineralization.

Soil $\mathrm{pH}$ was determined by a $\mathrm{pH}$-meter with glass electrode in a soil-water suspension using a 1:2.5 soil/water ratio; It mean $25 \mathrm{ml}$ of distilled water was added as 10 grams of soil was used; using $2 \mathrm{~mm}$ diameter soil aggregates; CEC was determined by using Nessler method on the soil already washed with ammonium acetate and ethanol $95 \%$, then percolated with $\mathrm{NaCl}$ $10 \%$; with $2 \mathrm{~mm}$ diameter soil aggregates; Soil organic matter content was determined by the drying of soil in the oven at $150^{\circ} \mathrm{c}$ three hours and calcinations at $450^{\circ} \mathrm{c}$ also three hours; using $0.5 \mathrm{~mm}$ diameter soil aggregates, the organic carbon is obtained by dividing the results of O.M by 1.724; Available Phosphorus was determined by using the Mehlich III method, with $2 \mathrm{~mm}$ diameter soil aggregates with the help of SSFA (Smart Soil Faster Analyzer); Potassium was evaluated following the K-kit method after percolation by ammonium acetate; Exchangeable Calcium and Magnesium was extracted following the EDTA $(0.01 \mathrm{~N})$ - method by titration by using the extract got after percolation by ammonium acetate; Total Nitrogen was analyzed by mineralization of the soil $0.5 \mathrm{~mm}$ sieved using concentrated sulphuric acids; Total exchangeable acidity was analyzed using titrimetric method. The soil of $2 \mathrm{~mm}$ sieved, was mixed with $50 \mathrm{ml}$ of KCL $1 \mathrm{~N}$ then the solution was titrated using $\mathrm{NaOH} 0.01 \mathrm{~N}$.

\subsection{Statistical Analysis}

The obtained data were managed in Microsoft Excel and later subjected to the analysis of variance (ANOVA) by using GENSTART statistical package and the means were significantly separated by using Duncan's Multiple Ranges Test (DMRT) and the Least Significant Difference (LSD) has been considered at 0.05 level of confidence. Differences at $F$ probability $<0.05$ were considered significant.

\subsection{Situation and Physical Characteristics of the Study Area}

This research has been carried out in Terimbere cell, Nyabirasi Sector, Rutsiro District, Western Province. Rutsiro District is one of the seven districts making up the Western Province, located at $150 \mathrm{~km}$ from Kigali. The altitude of the district varies between 1,400 meters at the edge of Lake Kivu and 2,600 meters beyond the top of Mount Crete Congo-Nile. It has a tropical climate with the average temperature is between $20^{\circ}$ and $24^{\circ} \mathrm{C}$. Rainfall increases gradually as we approach the mountains chain of the Congo-Nile covered by Gishwati forest. Rutsiro soil is basaltic, generally permeable and rich in iron. It is an acid soil $\mathrm{pH}$ with an average content of clay group karyokinesis [10].

\section{Results}

\section{1. pH-water, Organic Matter and Total Nitrogen}

The representatives mean values of $\mathrm{pH}$ water, Organic Matter and Total Nitrogen before (Not Terraced) and after terracing are illustrated in figure 1; and it varies from 6.02 to 5.91 for $\mathrm{pH}$ water; from $6.5 \%$ to $5.83 \%$ for organic matter and total nitrogen was ranged from $0.15 \%$ to $0.14 \%$.

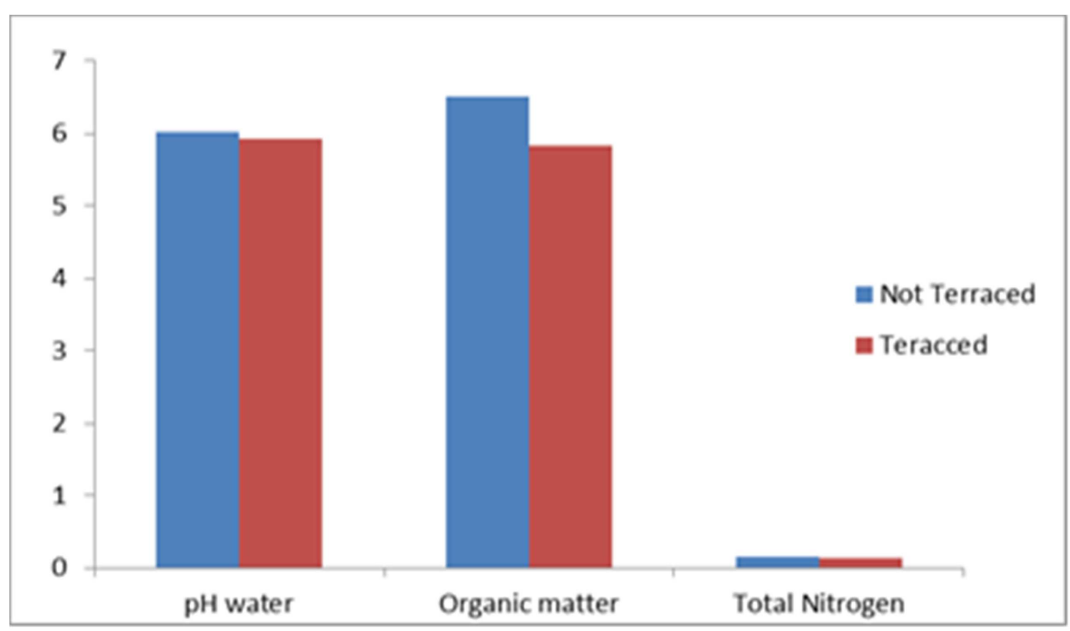

Figure 1. Soil pH Water, Organic Matter and Total Nitrogen. 


\subsection{Exchangeable Calcium, Magnesium and Potassium.}

The mean values of exchangeable calcium, Magnesium and Potassium before and after terracing varies from $4.03 \mathrm{meq} / 100 \mathrm{gr}$ to $3.83 \mathrm{meq} / 100 \mathrm{gr}$ for exchangeable calcium,
$1.70 \mathrm{meq} / 100 \mathrm{gr}$ to $1.1 \mathrm{meq} / 100 \mathrm{gr}$ for exchangeable magnesium and ranged from $0.34 \mathrm{meq} / 100 \mathrm{gr}$ to $0.29 \mathrm{meq} / 100 \mathrm{gr}$ for exchangeable potassium as it is illustrated in figure 2.

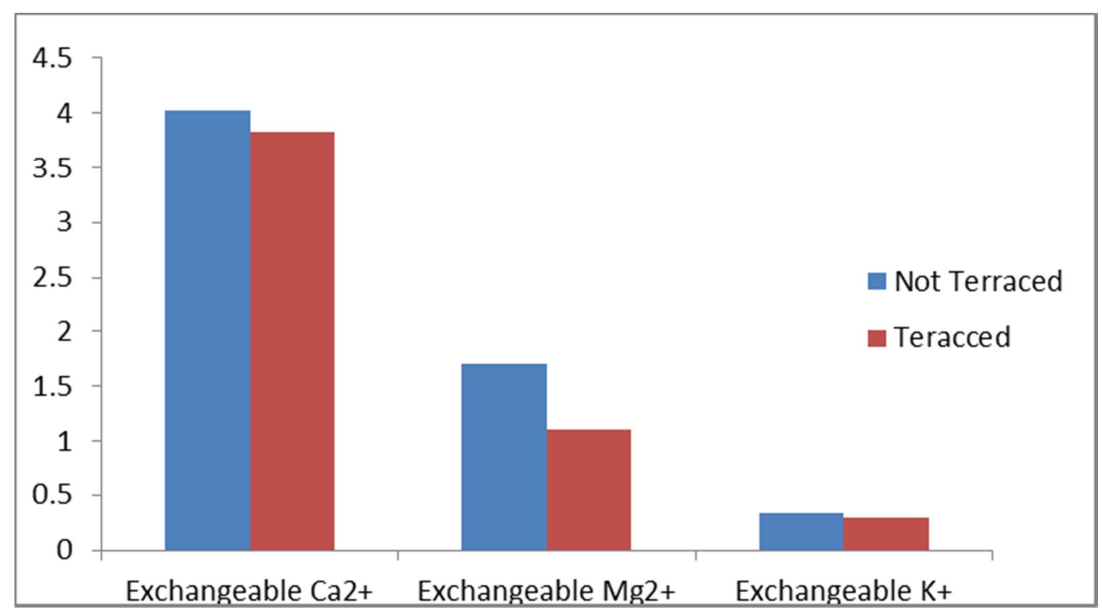

Figure 2. Soil exchangeable Calcium, exchangeable Magnesium and exchangeable Potassium.

\subsection{Available Phosphorous, Total Exchangeable Acidity and Cation Exchange Capacity}

The representatives mean values of available phosphorous, Total exchangeable acidity and cation exchange capacity (CEC) before (Not Terraced) and after terracing soil are represented in figure 3; and varies from $62.5 \mathrm{ppm}$ to $49.9 \mathrm{ppm}$ for available phosphorous; from $0.75 \mathrm{meq} / 100 \mathrm{gr}$ to $0.99 \mathrm{meq} / 100 \mathrm{gr}$ for total exchangeable acidity while cation exchange capacity varied from $32 \mathrm{meq} / 100 \mathrm{gr}$ to $29.36 \mathrm{meq} / 100 \mathrm{gr}$.

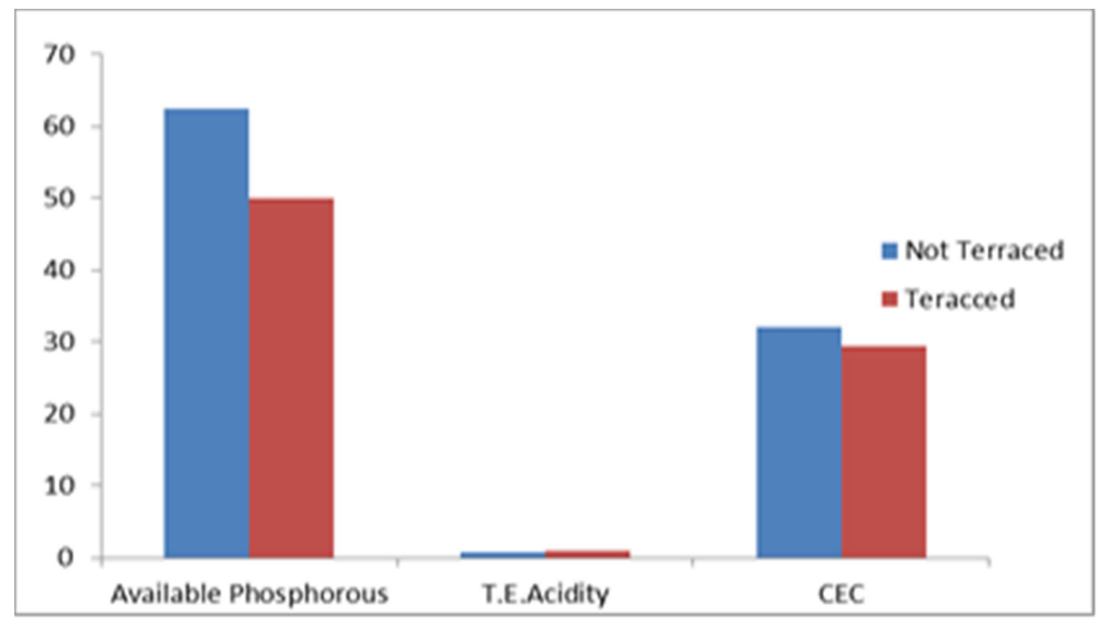

Figure 3. Soil available Phosphorous, Total Exchangeable acidity and Cation Exchange Capacity (CEC).

\section{Discussions}

Based on the result presented in (Figure 1), soil pH reduced, this reduction is due to works carried out during terracing this practice of mixing the soil particles of topsoil and deep soil increased the acidity level because deep layer which might be very acidic (low $\mathrm{pH}$ ) was mixed with the soil particles of topsoil and this was confirmed by saying that in the transformed plots, the acidity increased than in undisturbed as the upper horizons of soil receive maximum leaching by rainfall, and by dissolved carbonic and organic acids which remove metal cations (Calcium, potassium, magnesium) and replace them with $\mathrm{H}^{+}$ions [11]. That soil is subject to fairly acidic soil. [12]

The organic matter content shifted from $6.5 \%$ to $5.83 \%$ (figure 1), This decrease of organic matter is due to the terracing activity because both vegetation and organic matter rich topsoil were disturbed, as results this has caused the organic matter level to decline. In addition to this, practices which contribute to soil organic matter restoration such as use of manure, compost, organic residues have not been conducted after terracing. That soil is classified into humified soil [13].

The Total Nitrogen varied from $0.15 \%$ to $0.14 \%$ (figure 1 ) 
this lowering level is explained by the removal of crops which fix the nitrogen during terracing and to the lowering organic matter which contains all of the essential plant nutrients. That soil is subject to have middle total nitrogen [13].

The Results of Figure 2, showed a decrease of exchangeable $\mathrm{Ca}^{2+}, \mathrm{Mg}^{2+}$ and ${ }^{\mathrm{K}+}$ with the terracing effect. This difference is the results of the decreasing level of organic matter (which contains all of the essential plant nutrients); and this is also explained by the fact that weathered tropical soils contain lower amounts of $\mathrm{Ca}^{2+}$ and $\mathrm{Mg}^{2+}$ and ${ }^{\mathrm{K}+}$ [14]. In addition to that, the works carried out during terracing decreased the level of those ions due to the mixing of topsoil with subsoil, for the studied soil, exchangeable $\mathrm{Mg}^{2+}$ is classified from high to middle, high exchangeable calcium and middle exchangeable potassium before and after.

The Result of Figure 3, showed that the available phosphorus decreased, this is explained by the works carried out during terracing that compacted the soil, this compaction reduce the aeration and pore space in the root zone. This reduces Phosphorous (P) uptake and plant growth. Compaction also decreases the soil volume plants roots penetrate, limiting their total access to soil P.

Total Exchangeable Acidity (TEA) increased with the terracing effect (Figure 3). The decrease is related to the exchangeable base cations decrease and the exchangeable aluminium increase in the soils caused by acid deposition [15]. The results of the study area showed a decrease of $\mathrm{pH}$, CEC and basic cations which stimulate an increase of soil acidity after terracing.

The CEC also decreased due to the terracing effect (Figure 3). The decreasing CEC after terracing was also confirmed by the results found-by [15]; saying that in the transformed plots the cation exchangeable capacity (CEC) and base saturation (BS) decreased, and these are in agreements with obtained results. This decrease observed are also due to the lowering of organic matter in addition to the increasing acidity because the higher OM and clay content, the higher the CEC and also it has been observed that soil acidity diminishes the CEC [16].

The ANOVA results showed that significant differences occurred before and after terracing for $\mathrm{K}^{+}(\mathrm{F} . \mathrm{pr}=0.004)$ and for for $\mathrm{Mg}^{2+}(\mathrm{F} . \mathrm{pr}=0.027)$, the remaining parameters the result was not significant as F.pr was greater than the fixed level of confidence (F.pr $>0.05)$

\section{Conclusion}

This study was conducted on the impact of radical terracing on the chemical properties of soil and it shows that there is change caused by terracing effect. The obtained results show us that terracing have a negative impact on soil chemical properties of the soil. All the studied properties decreased except the total exchangeable acidity which increased, therefore, the soil after terracing needs improvement of its fertility and productivity; through sufficient agricultural inputs both mineral and organic.

\section{Recommendations}

Application of compost is recommended to increase the fertility level and improve the physical-chemical properties of the soil. Well prepared compost improve the structure of the soils and increase the water holding capacity and serving as a storehouse or supply of plant-nutrient elements, on top of the improvement of the fertility status of it, Organic manure must be applied in combination with inorganic fertilizers.

Leguminous should be planted after terracing because it serves to protect the soil from washing, The use of leguminous crops in a cultivation cycle is aimed at replenishing organic matter, at the same time adding any available nitrogenous material, and protecting soil during periods of high erosion hazard.

Lime should be applied, $\mathrm{Ca}(\mathrm{OH})_{2}$ to correct soil acidity; because When lime is added to acid soils, exchangeable and solution $\mathrm{Al}^{3+}$ is reduced by precipitation as $\mathrm{Al}(\mathrm{OH})_{3}$, which increases yield potential. It act also as a neutralizing agent but also it restores calcium on the soil particles.

\section{Acknowledgements}

We are highly indebted to all academic staff of the University of Lay Adventist of Kigali (UNILAK) for their skills provided and assistance towards the completion and success of this paper; We thank UR CAVM for it facilitation to use soil laboratory facilities; we are also gratefully to farmers of Nyabirasi for their detailed information for the sampling fields and warm communications during our field survey.

\section{References}

[1] Gupta, P. K., (2004). A Handbook of Soil, Fertilizer and Manure, $3^{\text {rd }}$ edition, Agrobios. Jodhpur (India). 591p. ISBN $\mathrm{N}^{\mathrm{o}} .: 81-7754-152-8$.

[2] Ramos, M., Roser F. and Casasnovas. A. M. (2007). Effects of land terracing on soil Properties in the Priorat region in Northeastern Spain: A multivariate analysis. Geoderma 142 (2007) 251-261. Spain.

[3] Lal, R., 2014. Desertification and soil erosion. Glob. Environ. Change 1, 369-378.

[4] Bai, Z. G., Dent, D. L., Olsson, L., Schaepman, M. E., 2008. Global assessment of land degradation and improvement. 1. Identification by Remote Sensing. International Soil Reference and Information Centre (ISRIC), Wageningen, 70pp.

[5] Nachtergaele, F., Petri, M., Biancalani, R., Van Lynden, G., Van Velthuizen, H. 2010. Global Land Degradation Information System (GLADIS). Beta Version. An Information Database for Land Degradation Assessment at Global Level. Land Degradation Assessment in Drylands Technical Report, 17. Food and Agriculture Organization of the United Nations (FAO), Rome. 
[6] FAO, 2015. Crop Prospects and Food Situation. [Online] URL: http://www.fao.org/3/a-I4410E.pdf (accessed 12.4.2019).

[7] MINAGRI, (2002). Etude sur la protection des bassins versants et la conservation des sols, Kigali, Rwanda. 36p.

[8] LWH, 2008. MINAGRI (2002). Etude sur la protection des bassins versa et la conservation des sols, Kigali Rwanda. P36.

[9] MINAGRI, (2004), Plan stratégique pour la transformation de l'agriculture au Rwanda. Kigali. Rwanda.70p.

[10] Rutsiro district report, (2012). District development plan.

[11] McLean, EO. (1982). Soil pH and lime requirement. Madison, Wisconsin. america.

[12] Raymond, W., Miller and Roy, L., Donahue, (1990), SOILS:
An introduction to Soil and Plant growth, $6^{\text {th }}$ edition, Prentice Hall. New Jersey 07632, USA. 768p.

[13] Mutwewingabo et Rutunga, (1987). Etude des sols de l'essai d'intensification de l'agriculture de Gikongoro. Rwanda. 87p.

[14] Halvin, J. L., Tisdale, S. L., Beaton, J. D. and Nelson, W. L., (2005). Soil fertility and Fertilizers: An introductory to nutrient management. $7^{\text {th }}$ edition. Prentice Hall. New Jersey 07458. USA. 515p.

[15] Zhaohua, D., Yunxia, L., Xingiian, W., and Dianwu, Z., (1997). Changes in $\mathrm{pH}, \mathrm{CEC}$ and Exchangeable acidity of some forest soils in Southern CHINA. Water, Air, and Soil Pollution 108: 377-390. China.

[16] Defoer, T., Budelman A., Toulmin C., and Carter E., (2000). Managing soil fertility in the tropics. 